\title{
Pessoa, um mistério não decifrado e em permanente desvelar: crítica aos dualismos cartesiano e estrutural tangenciando a ética e a pastoral cristã
}

\author{
The self, a mystery not deciphered and in permanent \\ unveiling: a critique on cartesian and structural \\ dualism tangential ethics and Christian pastoral
}

\section{Gerson Joni Fischer*}

Faculdades Batista do Paraná (FABAPAR), Curitiba, PR, Brasil

\section{Resumo}

Há um Eu que controla a sua própria casa, o corpo? É possível, com base nos conhecimentos acerca do cérebro, assumir o ser humano como uma máquina biomolecular que funciona de modo determinado? Há um consenso de que é por meio do cérebro que ocorrem os processos mentais e não na alma, como no dualismo clássico. Pode-se, entretanto, reduzir ao pequeno órgão cinzento a explicação pela emergência da vida consciente? Reduzir o entendimento do evento contribui para a defesa do valor do humano, para uma compreensão deste como responsável por suas decisões e atos? A pessoa é um mistério não decifrado. Critica-se o conceito de pessoa que imperou na modernidade, mas também o uso totalizante do princípio de causa e efeito. A presente abordagem recebe o humano como uno e 
dual. 0 cérebro e a mente surgem como fatos distintos, porém, indivisíveis. Pessoas não possuem, são almas viventes. 0 atual estágio dos debates sugere que o dualismo cartesiano e o monismo reducionista não se apresentam como alternativas. É a pessoa toda quem percebe, pensa, recorda, emociona-se, motiva-se, é atenta e produz impulsos. A vida diária revela que se é tudo isto que se apresenta de modo inseparável. O diálogo proposto é posto a serviço das refinadas descobertas acerca da anatomia e da fisiologia do cérebro e do uso ético destas, bem como da afirmação do ser humano, que as transcende. Sob o ponto de vista da tradição bíblica, o testemunho de Deus jamais é dualista, fazendo-se perceptível sempre de modo encarnado.

Palavras-chave: Ética. Dualismo cartesiano. Dualismo estrutural. Pessoa. Pastoral cristã.

\section{Abstract}

Is there a Self who controls its own dwelling, the body? Is it possible, based on what is known about the brain, to perceive the human being as a biomolecular machine that functions in a certain manner? There is consensus that mental processes occur in the brain; not in the soul as in classic dualism. Is it possible, however, to abbreviate the explanation of the emergence of conscious life to the small grey mass? Does minimizing knowledge of this event contribute to defending the value of the human being and to comprehending that he is responsible for personal decisions and acts? The self is a mystery to be deciphered. There is criticism of the concept of the self which prevailed in modern times, but also, that of the holistic use of the principle of cause and effect. The present approach views the human being as single and dual. The brain and the mind emerge as distinct, yet indivisible factors. Persons do not have, but rather, are living souls. In their current stage, debates suggest that Cartesian dualism and reductionist monism are not presented as alternatives. It is the self who perceives, thinks, remembers, feels, is motivated, attentive and produces impulses. Daily life reveals that one is all these things which are presented in an inseparable manner. The proposed dialog shows itself in favor of the refined discoveries regarding brain anatomy and physiology and their ethical implications. It is supportive of the affirmation of the self which transcends these discoveries. Under the light of Biblical tradition, the testimony of God is never dualistic. It is always made to be perceived as incarnate.

Keywords: Ethics. Cartesian dualism. Structural dualism. Self. Christian pastoral. 


\section{Introdução ${ }^{1}$}

Há um Eu imortal que controla o corpo mortal como sua extensão, no qual habita? Existe uma alma, de substância específica, espiritual, passível de ser mensurada, a exemplo do que pode ser feito com o corpo, em suas características anatômicas e físicas? A discussão não é nova. Trata-se de um tema recorrente entre estudiosos do cérebro desde o século XVIII, mas que, de modo especialmente intenso, se encontra em disputa desde fins do século XX, enquanto resultado de pesquisas recentes acerca do funcionamento deste pequeno órgão cinzento que reside no interior da abóbada craniana. No âmbito da filosofia, o assunto vem sendo debatido nos domínios das ciências do espírito, com o objetivo de responder ao clássico problema da relação entre corpo e alma; hoje conhecido como "problema cérebro e mente", assim posto em função de questionamentos levantados por neurocientistas contemporâneos (FISCHER; FACION 2011, p. 291-293). Verifica-se, nos debates e nas publicações que a esse respeito se multiplicam, o esforço em superar os impasses que ainda se mantêm em uma das fronteiras mais sensíveis do conhecimento, ainda não satisfatoriamente sujeitas à lei da física da causalidade: o humano, sua consciência e comportamento. O dualismo cartesiano ${ }^{2}$ de corpo e alma já não encontra receptividade entre os pensadores que se envolvem com este objeto de pesquisa ${ }^{3}$.

1 A abordagem temática aqui proposta foi apresentada no Grupo de Trabalho: Corpo, alma e espírito: o ser humano integral e fez parte do programa do VIII Congresso Internacional em Ciências da Religião (Goiânia, 26 a 29 de abril de 2016). 0 Congresso realizado obteve apoio de várias instituições relacionadas com ensino e pesquisa e foi promovido pela PUC Goiás. 0 paper da Comunicação foi integrado aos Anais do Congresso e aqui se encontra revisto e ampliado em forma de artigo. 0 assunto vem recebendo a atenção do presente autor em anos recentes, tendo sido proposto em distintas publicações, sempre com ênfases que se complementam, de natureza interdisciplinar e teológico-pastoral. Menciona-se aqui, por exemplo, o seguinte artigo "A pessoa: fenômeno causal ou espontâneo? Exame crítico das objeções de Ansgar Beckermann à existência da alma" (FISCHER, 2013a).

2 Expressão relativa à proposta elucidativa de Descartes (1596-1650) a respeito do enigma que ronda a compreensão do humano.

3 John C. Eccles (1903-1997) é considerado o último neurobiólogo de expressão que defendia, ainda em fins do século passado, o dualismo de corpo e alma. ECCLES, J. C. Wie das Selbst sein Gehirn steuert. 2. Ed. München: Piper, 1997.

Rev. Pistis Prax., Teol. Pastor., Curitiba, v. 10, n. 2, 394-414, maio/ago. 2018 
Pergunta-se, no entanto, se é admissível limitar a pessoa a um raciocínio que a põe na condição de máquina biomolecular, que funciona de modo determinado. Embora não mais se sustente a existência de uma alma que, de modo distinto, interatua com o corpo como seu invólucro e prolongamento - uma vez que jamais foi localizada enquanto uma espécie de "órgão" diverso - objetiva-se defender, por meio da presente crítica, que esta não pode ser recusada enquanto manifestação da própria existência; um fenômeno que atribui sentido único ao humano. Toma-se emprestada uma ideia apoiada por alguns cientistas da natureza e filósofos da atualidade, a de uma causalidade aberta (DROSSEL, 2013) que agrega a dimensão teleológica quando o assunto é compreender o ser humano (NAGEL, 2013), em sua busca permanente de atribuir sentido à sua vida.

O reducionismo materialista monista de cérebro e mente - uma nova versão de dualismo, estrutural — não se apresenta como alternativa ao cartesianismo clássico, quando o intento é adentrar ao mistério que constitui o humano. Esta hipótese é, no presente trabalho, tangenciada por duas preocupações que se relacionam de modo interdependente: a primeira é de ordem ética e a outra de pastoral. Quanto à ética, faz-se coro com a percepção de Caspary, ou seja, que os neurocientistas não podem manter tudo o que prometem. Se todo o comportamento humano pudesse ser explicado com base no funcionamento do cérebro, necessariamente teria que se fazer uma revisão radical dos códigos penais atuais, não haveria liberdade de escolha e a imagem que se faz da presença de homens e mulheres no mundo teria que, enquanto seres racionais e responsáveis por seus atos, ser bem outra $(2010)^{4}$. No que se refere à pastoral, aqui referida à tradição cristã, afirma-se que somente a pessoa tomada em sua unidade, como alma vivente, justifica o interesse pelo cuidado do outro. $\mathrm{O}$ evangelho da reconciliação exige práticas que se revelem como sendo eticamente situadas, que penetrem o recôndito da existência humana e promovam comunhão intersubjetiva e vida plena (FISCHER, 2013b, p. 100).

40 título da obra, no original em língua alemã, é assim traduzido: "Tudo neuro? 0 que a neurociência promete e não pode manter". 


\section{0 cartesianismo de substância e o dualismo oculto: perguntas não respondidas e os perigos do reducionismo materialista}

Há um consenso entre pesquisadores que com a concorrência do cérebro é que se desenvolvem os processos conscientes e inconscientes da vida de uma pessoa; não por meio de uma presumida alma que comanda o corpo como que "do lado de fora", enquanto uma espécie de "órgão" soberano, a exemplo do conceito de mente ${ }^{5}$ de Descartes (FISCHER, 2013a, p. 64-76). A ideia pode ser resumida por meio de uma obra bibliográfica organizada por Volgelsang e Hoppe, intitulada: "Sem o cérebro nada é" $(2008)^{6}$. Desde os experimentos de Benjamim Libet na década de 80 do último século, generaliza-se a percepção de que o dualismo cartesiano não pode ser mantido enquanto uma hipótese racional. Os mesmos "assinalaram os processos que ocorrem no cérebro, antes mesmo que uma decisão consciente se transforme em uma ação, indicando, desse modo, que a liberdade encontra-se condicionada a antecedentes neurais" (FISCHER; FACION, 2011, p. 300) ${ }^{7}$, o que, porém, não confere a estes, obrigatoriamente, um status de culto, como bem observou Caspary:

A configuração do experimento de Libet é já problemática a partir deste ponto de vista. Ela não considera que o ser humano é de pouca confiança; ele, afinal, não é um Bio Autômato, porém, fonte de pura perturbação. Libet, porém, se fixa em, como Hagner observa, 'autenticidade, credibilidade e confiabilidade'. Ele se apresenta como um bom cientista da natureza, que deseja, no experimento, descrever as pessoas como máquinas que não interferem no procedimento em teste - o que, com certeza, se restringe a um itento bem intencionado. As pessoas são falíveis, também pesquisadores do cérebro (2010, p. 31) ${ }^{8}$.

5 É interessante observar que no idioma germânico o termo que se traduz por mente também pode ser exprimido pelas palavras alma e espírito (Geist). GEIST. In: LANGENSCHEIDT, 2001.

60 título sugestivo e completo do compêndio de artigos organizado pelos autores mencionados é: "Sem o cérebro nada é. Impulsos para uma neuroética”, do original: "Ohne Hirn ist alles nichts. Impulse für eine neuroethik".

7 Ver LIBET, 2004, p. 268-289.

8 Ver especialmente as páginas 11 a 32 do autor citado.

Rev. Pistis Prax., Teol. Pastor., Curitiba, v. 10, n. 2, 394-414, maio/ago. 2018 
O modelo atualmente em vigor para elucidar o funcionamento do cérebro é aquele que aponta para a interação dos neurônios em rede. Este sustenta a hipótese de que uma complexa comunicação neural, formada e herdada pelas gerações de seres humanos ao longo do curso evolutivo, em contínua ampliação ${ }^{9}$, responde pelo fenômeno mental; a saber, a percepção, o pensamento, a memória, a emoção, a motivação, a atenção, o impulso, enfim, todos os elementos constitutivos da consciência humana. A teoria explicativa empregada é aquela que afirma haver um continuum entre cérebro e mente, integrado ao corpo, inserido ao meio externo e por este impulsionado (MORA, 2004). Discorda-se com veemência do projeto desenhado por Descartes, no qual se defendia a existência da alma e isto, diante do argumento de que sua presença nos seres humanos, - em forma de matéria ou energia - não pode ser provada pelo método que orienta as ciências naturais, isto é, a lei de causa e efeito (FISCHER, 2013a, p. 6476; BECKERMANN, 2008, p. 9-53).

No entanto, como bem realçaram Tretter e Grünhut (2010, p. 9495), dificilmente se encontra hoje alguém que indague se de fato pode ser a base neural a produtora, causadora, dos fenômenos mentais, problematizando, desse modo, o pressuposto descrito anteriormente. Em verdade, o pensamento é sempre imbricado por conteúdos que envolvem intenções e este pensar se faz nas relações que uma pessoa estabelece com o seu meio, de modo que a pergunta sobre a origem dos fenômenos mentais permanece aberta, um mistério não decifrado. Tal não suscita a exigência que se rejeite, por outro lado, a ideia de que neurônios que funcionam em rede se apresentam como indissociavelmente relacionados ao raciocínio e aos significados que uma pessoa atribui às suas experiências:

O conceito de causalidade, já no plano da linguagem, esconde uma série de problemas que, raramente, são observados no debate mente-cérebro: É frequente falar-se sobre as 'bases' neurais, os 'fundamentos' neurais dos fenômenos psíquicos, sem que se esclareça se os fatores neurais são os 'produtores', os 'causadores', os 'condicionadores' ou 'determinadores'

9 A ideia em curso é que tudo o que constitui a experiência humana, emanada da comunicação neural, deixa, por sua vez, marcas no cérebro, ampliando as suas múltiplas vias de ligação, também conhecidas por sinapses neurais (MORA, 2004, p. 17-30). 
dos estados e processos mentais. De particular importância é a eficácia do conteúdo conceitual dos estados intencionais: 'Nossos pensamentos possuem um conteúdo conceitual específico, e eles afetam os nossos comportamentos, devido ao seu conteúdo conceitual. O conteúdo conceitual de um estado intencional é estabelecido por meio de determinadas relações da pessoa com o seu meio. O Externalismo social indica que o pensamento é dependente da linguagem e este, um assunto de uma comunidade social. As qualidades intencionais são funcionais, a saber, qualidades funcionais sociais (ESFELD, 2008, p. 38)'. (TRETTER; GRÜNHUT, 2010, p. 94-95) ${ }^{10}$.

Continua, portanto, sem resposta a pergunta sobre como, na teoria desenhada, se eleva o fenômeno da consciência da base neural de uma pessoa. Até o momento presente não se evidenciou como estímulos neurais operam, transformando-se em fatos mentais. O que se pode verificar é uma majorada ambição quando o tema envolve compreender o mistério que envolve a vida humana consciente. Os conhecimentos disponíveis acerca do funcionamento do cérebro, ainda que em ascensão, não são suficientes para fazerem-se afirmações fechadas a esse respeito. É disseminada a mensagem que tudo será esclarecido em um futuro próximo, inclusive a impossibilidade da liberdade de escolha e ação de uma pessoa ${ }^{11}$. Basta, para tal, que se prossigam investindo pesados recursos em pesquisa (TRETTER; GRÜNHUT, 2010, p. 35).

O que se estima no presente trabalho é que recusar o dualismo cartesiano de substâncias não afiança que a compreensão do mistério que transforma um ser em pessoa se uniformize. Os fenômenos mentais não se deixam reduzir por um fisiologismo materialista, uma vez que cada pessoa prossegue vivenciando sua subjetividade de modo único. Os argumentos calcados na causalidade não são suficientes para enquadrar motivos e experiências pessoais. O cognitivismo, que atribui o mental como uma construção de um cérebro supostamente apto para tal, não supera o velho modelo explicativo de estímulo-resposta do behaviorismo:

10 Os autores não rejeitam que o funcionamento do cérebro, como uma rede de neurônios comunicantes, esteja completamente envolvida na organização dos pensamentos. 0 que se questiona é, no entanto, a tendência a se reduzir o debate cérebro-mente ao princípio de causalidade (TRETTER; GRÜNHUT, 2010, p. 94-95).

11 Admite-se a liberdade de escolha e ação enquanto uma determinação cerebral. Esta hipótese é apresentada e problematiza na sequência do presente artigo. 
Enquanto análise do mental, no entanto, todas essas teorias são inadequadas. Elas desconsideram algo que é decisivo, ou seja, o que está posto para além dos motivos do observador externo. Outras condições mentais precisam ser consideradas, a saber, o aspecto dos fenômenos mentais, o qual fica evidente a partir do ponto de vista da primeira pessoa, a partir da perspectiva interior do sujeito consciente: por exemplo, qual é para este o gosto do açúcar, como lhe parece a cor vermelha ou como sente a raiva. Isto evidencia ser algo mais do que reação comportamental e capacidade de diferenciação que explicam esta vivência. O behaviorismo não considera o estado mental interior (NAGEL, 2013, p. 59-60).

Entre os muitos debates e publicações acerca da temática aqui aventada, é possível constatar a conservação da estrutura de pensamento que caracteriza o dualismo cartesiano. Em outras palavras, segue-se raciocinando de modo polarizado, a exemplo do binômio cérebro e mente; oferecendo-se este tão somente como um substitutivo de seu predecessor, corpo e alma (FISCHER, 2013a, p. 76-85). A crítica que se vem sendo feita a neurobiólogos e filósofos naturalistas, entre outros, é que perpetram um dualismo oculto (criptocartesianismo), a saber, quando o esforço consiste em reduzir tudo que perfaz a essência e existência da pessoa à sua base neural; um pretenso monismo que esconde um modo de pensar tipicamente dualista, repetindo: mente e cérebro. Destacam-se aqui, entre os muitos críticos, Maxwell Bennett, Peter Hacker (BENNETT et al., 2010), Thomas Nagel (2013) e Peter Janich (2009), em sua contestação ao que acima se nominou de fisiologismo materialista reduzido em relação à compreensão do humano:

Eu tenho um corpo e estou no crânio de meu corpo. Esta é uma variável materialista do cartesianismo. Um motivo central, devido ao qual escrevemos nosso livro, é a firme convicção de que os neurocientistas modernos bem como muitos filósofos ainda permanecem na ampla e escura sombra de Descartes. Pois embora recusem a substância imaterial da alma cartesiana, transportam suas características sobre o cérebro humano, com o que deixam intacta por inteiro a equivocada concepção cartesiana da relação entre alma e corpo. Nossa recomendação dirige-se no sentido de que os neurocientistas e também os filósofos abandonem o domínio da sombra cartesiana e procurem a luz do sol aristotélica, na qual se pode enxergar muito melhor (BENNETT et al., 2010, p. 230). 
Em que consiste a diferença entre o cartesianismo clássico de corpo e alma e sua versão oculta, isto é, do discurso cérebro e mente? Por que a ideia propagada de que esteja havendo uma mudança em curso quanto à compreensão do que é a pessoa, com auxílio das descobertas dos neurocientistas em relação ao funcionamento do cérebro, não soluciona o problema do dualismo, que se mantem na estrutura das reflexões voltadas a esse debate?

Os argumentos de Ansgar Beckermann, filósofo que defende a teoria naturalista materialista acerca do que constitui a pessoa, se oferecem como exemplo e porta de acesso para reagir às indagações acima. Este alterca que não se traduz em contradição prosseguir arguindo a favor da existência de um eu, não mais, entretanto, na acepção que se tornou comum no pensamento ocidental, no qual este - a alma - era compreendida como uma substância espiritual à parte e em interação com o corpo. A ideia agora é traduzir a concepção de um eu que venha a ser impresso em letras minúsculas, uma versão alternativa à imagem de pessoa que vigora no senso comum e vem sendo abandonada nos meios intelectuais. Assim concebido, este eu, a consciência com todos os elementos que o constituem, não vem a ser um ente, mas um fato causal que emerge dos processos neurais que encontram seu núcleo no cérebro (2008).

Em sua inferência filosófica, que se pretende inspirada nos atuais conhecimentos acerca do funcionamento do cérebro, Beckermann entende que os "seres humanos [...] são integralmente entes biológicos, nada contribuindo na observação destes a algo que leve a supor a existência de uma alma criada à imagem e semelhança de Deus, imaterial, imortal e que sobrevive à morte do corpo" (FISCHER, 2013a, p. 64). De maneira que, referir-se a um Eu iniciado em caractere maiúsculo, obedeceria a prosseguir aceitando a existência de uma alma, morando em um corpo. O autor não rejeita as aptidões mentais dos seres humanos, que estes são aptos para compor uma imagem do mundo e de si mesmos, porém, nega haver almas, "eus" ou "sis" formando o núcleo destes (BECKERMANN, 2008, p. 85-86).

A tese que reduz a pessoa à sua realidade anatômica e fisiológica não necessariamente pressupõe, portanto, a negação da mente. Os 
neurobiólogos mais extremistas ${ }^{12}$, que defendem um determinismo neural radical e que situam a mente como pura ilusão, rejeitando, desse modo, a consciência e a liberdade humanas, são contrapostos por neurofilósofos que, a exemplo de Beckermann, procuram um caminho de conciliação entre o que vêm afirmando, mais recentemente, neurocientistas e, historicamente, uma parcela da tradição filosófica ocidental:

- Pessoas são entes que percebem, recordam, sentem dor e alegria, refletem e se deparam com decisões.

- Ao menos algumas vezes, são elas mesmas que refletem, decidem e fazem algo.

- Ao menos algumas vezes, são elas livres em suas decisões e ações, de modo que são também responsáveis pelas mesmas (BECKERMANN, 2008, p. 53) $)^{13}$.

Esta trajetória "harmonizadora", entretanto, mantem-se na velha perspectiva cartesiana dualista. Rejeita-se a existência da alma como uma substância espiritual, ou seja, de um Eu presente no corpo, mas à parte e acima deste, por jamais ter sido identificado pelas ciências empíricas sujeitas à lei de causa e efeito, permanecendo-se, porém, a discorrer sobre o assunto com base em uma composição dualista, na qual se transfere as especificidades da mente sobre o cérebro humano (BENNETT et al., 2010, p. 230). A interação dualizada entre cérebro e mente é permanentemente alimentada, justamente porque, como já afirmado, a mente não se deixa reduzir devido às suas qualidades intencionais.

12 SINGER, W. Ein neues Menschenbild? Gespräche über Hirnforschung. Frankfurt am Main: Suhrkamp, 2003. Para este neurofísico que radicaliza a discussão em questão, cientistas do cérebro somente podem analisar os fenômenos da mente enquanto observadores. Esta é a nominada perspectiva da terceira pessoa, que difere do ponto de vista da primeira pessoa, onde o indivíduo explica e dá sentido às suas próprias experiências. 0 cientista afirma: "No modo de interpretar dos cientistas da natureza, a perspectiva da terceira pessoa, não existem estes fenômenos" (2003, p. 25). Singer, evidentemente, se orienta pelo método empírico que se funda na lei da causalidade, no qual não há espaço para filosofar sobre a mente, a existência de um centro aglutinador que se denomine de Eu. 0 que se pode observar de modo empírico são somente processos neurais (2003, p. 24-34), de maneira que se adentra, sob este ponto de vista, em especulações filosóficas quando se fazem afirmações não passíveis de análise experimental.

13 Observação: a tradução destas conclusões de Beckermann é livre, entretanto, mantem as ideias defendidas pelo filósofo. 
Como Beckermann, vários neurofilósofos ${ }^{14}$ buscam hoje essa referida via conciliadora. Nela, nega-se que o determinismo ${ }^{15}$ anteposto no modelo de comunicação neural se oponha à capacidade inerente do indivíduo em fazer escolhas de modo livre e responsável. Abraça-se a hipótese de que é possível defender a "existência" de um eu que, aos menos algumas vezes, reflete, decide, faz algo, é livre e responsável. Porém, afinal, como emerge a consciência do substrato neural? (FISCHER; FACION, 2011, p. 293-298; FISCHER, 2013a, p. 76-85).

Reduzir o entendimento de quem é a pessoa ao substrato neural não contribui para a defesa de seu valor, enquanto ser livre e responsável por suas decisões e atos. De que maneira prosseguir confirmando o mandamento do amor testemunhado pela fé cristã $(1 \text { Jo } 4,19)^{16}$, uma vez que o indivíduo passe a ser recebido como menos do que uma pessoa? Não seria o dualismo estrutural camuflado de monismo uma expressão contemporânea de uma cultura desencantada com a moral cartesiana moderna do dever? Não haveria um caminho alternativo para se refletir sobre o tema, sem que se obrigue a rejeitar o modelo causal aplicado à compreensão humano, porém, sem o tornar absoluto? A busca de entendimento da natureza humana não poderia contemplar a admissão e o respeito ao mistério nunca totalmente decifrável que o constitui? (FISCHER; FACION, 2011, p. 298-300; FISCHER, 2013a, p. 85-87; GEYER, 2004, p. 9-19):

Eu temo, todavia, que um abandono do livre-arbítrio iria atingir mais fortemente o conceito que temos de nós mesmos e nossa cultura do que os defensores da naturalização estão conscientes e do que eles próprios gostariam. Eu defendo o livre-arbítrio, além do mais, porque eu não enxergo outra possibilidade de fundamentar o valor da vida humana. Se a pessoa

14 Outro exemplo de filósofo contemporâneo que segue em direção idêntica de Beckermann é Michael Pauen. Para este pensador, rejeitar o determinismo implica em se aceitar que a mente seria uma manifestação do acaso: "Nós, seres humanos, somos aptos - mais do que todos os outros seres vivos - a propor alvos autônomos, à consideração de normas, a ponderar entre fins concorrentes e a planejar ações de longo prazo. A evolução de nosso cérebro o possibilitou e com isto criou a condição prévia para, em um sentido concreto, uma liberdade crescente; ela consiste em ponderar entre opções de ação e encontrar uma alternativa autodeterminada" (PAUEN; ROTH, 2008, p. 174).

150 determinismo do modelo cérebro e mente equivale à sujeição deste debate à lei da causalidade, no qual a mente surge como 0 efeito da comunicação neural, sua causadora.

16 "Nós amamos porque ele nos amou primeiro" (1Jo 4,19 NVI).

Rev. Pistis Prax., Teol. Pastor., Curitiba, v. 10, n. 2, 394-414, maio/ago. 2018 
nada mais é do que um organismo particularmente complexo, se, inclusive, esta complexidade pode ser superada por máquinas, o que fica então do valor inviolável e imponderável de uma pessoa? (BECKER, 2009, p. 255-256).

\section{Pessoa: um mistério não decifrado e em permanente desvelar}

A pessoa se constitui em mistério não decifrável por completo, ser integral em contínua revelação. Aproximar-se à sua compreensão exige, de um lado, experiência e, de outro, conhecimento. Em um esforço de imaginação, representa uma viagem que tem início, entretanto, não um fim. Demanda, além disso, que se agregue uma conotação de complementariedade ${ }^{17}$, ilustrado com o que se dá em relação à rotatividade da Lua e no que diz respeito à luz solar, que se faz refletir em sua superfície. O que em determinado tempo e lugar dela se pode ver a partir da Terra, é tão só o nível que se encontrava iluminado. Este plano alumiado, entretanto, devido à rotação do satélite, volta à escuridão, não por último devido à perspectiva dos que estão enxergando a parte irradiada pelo Sol em perspectiva de um lugar específico da Terra. Ademais, outro dado significativo, é que o ainda envolto em trevas vai se manifestando aos olhos atentos de seus observadores. A pessoa é este complemento de enigma e conhecimento, em processo de saída e chegada permanente (ESPINOSA, 2008, p. 17-21). É mistério, porque na ótica do ser que faz suas próprias experiências, atribuindo-lhes sentido, não é passível de ser acessado; a assim nominada perspectiva da primeira pessoa. É conhecimento, porque se dá a conhecer, compartilhando sua existência com outros seres que lhe são semelhantes; a perspectiva da terceira pessoa (NAGEL, 2013, p. 59-60).

Submete-se na contemporaneidade ao crivo da crítica a compreensão de pessoa que dominou na era moderna, isto é, o dualismo de substâncias, espiritual e material, da alma que comanda o corpo como sua extensão, a ela sujeito. Porém, o dualismo que se oculta detrás da fala naturalista e materialista de cérebro e mente na atualidade, apenas

170 conceito de complementariedade aqui adotado não é o de algo a ser anexado a uma realidade maior, enquanto um fator acessório e de menor importância. Antes, implica em considera-lo como um componente que segue em paralelo, sem o qual, no estudo em questão, o conhecimento da pessoa não seria possível. 
supostamente de caráter monista, também é passível de questionamento. Este mantem a mesma estrutura de pensamento típica do cartesianismo e se encontra apenas parcialmente elucidado pela lei de causa e efeito. Neste caso, quem determina e comanda é o cérebro, supostamente o causador da liberdade de decisão típica da esfera mental.

Em meio a suas considerações sobre a intencionalidade da mente, o filósofo John Searle admite que o assunto em disputa se acha imerso em desencontros (2006, p. 353-355). Declara que, ao invés de se deixarem orientar pelos métodos de averiguação em vigor, os pensadores do tempo presente deveriam manter-se em atitude de permanente discussão. Porém, ainda que sua atitude em relação ao complexo tema seja de diálogo, assevera que "processos cerebrais causam a consciência em todas as suas formas" (SEARLE, 2006, p. 354); sentença esta que considera "a compreensão de que o cérebro é a única coisa lá dentro, e que o cérebro causa consciência [...]" (SEARLE, 2006, p. 354). Em outras palavras, o suporte estrutural da discussão se mantem no plano dualista.

A percepção e entendimento que se postula no presente artigo é outra. A indicação de Maxwell Bennett e Peter Hacker, referida no tópico anterior, é aqui mais uma vez mencionada, ou seja, de que neurocientistas, bem como filósofos, se distanciem da "sombra cartesiana" e procurem a "luz do sol aristotélica", pois nesta se pode tratar do tema em discussão por outro viés (BENNETT et al., 2010, p. 230). A visão é aquela que admite a alma humana como a vida que se manifesta no corpo, ou melhor, a pessoa não tem alma, é alma vivente, é corpo e alma. A vida e o corpo apareceriam desse modo como complementares, em acepção já ilustrada.

No "modelo aristotélico clássico, o corpo seria a matéria e a vida, a forma”. (FISCHER; FACION, 2011, p. 301). Eu "[...] sou tudo isto que se apresenta como realidade inseparável” (FISCHER, 2013a, p. 79). Assume-se o subsequente manifesto paradoxal: "a mente é [...] nem uma substância diferente do cérebro, ainda com o cérebro idêntica”. (BENNETT et al., 2010, p. 19). Neste modelo interpretativo não há como dividir alma e corpo, nem antagonizá-los, por se apresentarem como uma unidade. A vida não pode ser pensada fora do corpo, nem a pessoa a parte desta unidade paradoxal. Homens e mulheres são, por inteiro, organismos vivos. A complementaridade envolve uma perspectiva intra e inter-relacional, uma 
vez que a pessoa que tem consciência de si é a mesma que se revela a seus semelhantes. Não é adequado dividir o que se encontra, por natureza, unido. Reduzir a vida, entretanto, ao corpo físico, como que dele emanando de modo determinista, não se apresenta como alternativa, uma vez que a tendência a se dualizar reaparecerá na estrutura de pensar sobre o assunto. Não há porque não considerar o Eu iniciado em letra maiúscula, uma vez que a ideia seja a de considerar a pessoa como este organismo vivo.

Searle está de acordo com esta alternativa explicativa de Bennett e Hacker, afirmando se tratar de um modo tolo de arrazoar sobre a pessoa, assumindo-a sem esclarecimento (BENNETT et al., 2010, p. 139-175). É isto, no entanto, que se afiança na presente discussão, ou seja, homens e mulheres apresentam-se como mistério a "ser abraçado"; experiência e conhecimento, complementaridade nos limites do enigma e do desvelamento. Em outros termos, pessoas são seres vivos que não podem ser reduzidos a uma de suas partes:

Nós seres humanos dispomos de uma vasta gama de habilidades mentais, disponibilizados em vida para serem mobilizados e isto quando se trata de perceber, pensar e considerar, sentir emoções, desejar coisas, forjar planos e tomar decisões. O fato de termos estas capacidades nos define como entes vivos, que efetivamente somos. As condições e as circunstâncias da existência, bem como o exercício de tais poderes podem ser pesquisadas. Essa é a tarefa da neurociência, que descobre sempre mais sobre isto. Mas suas descobertas não alteram a verdade conceitual de que essas habilidades e seu exercício no perceber, pensar e sentir são características das pessoas, e não propriedades de suas partes, especialmente, não do cérebro. O homem não é um cérebro incorporado no crânio de um corpo, mas uma unidade psicofísica, um ente vivo, que percebe, atua de modo intencional, toma decisões, pode se emocionar [...] (BENNETT, et al., 2010, p. 19-20).

A consideração é que o humano é, paradoxalmente, uno e dual, ou melhor, unidual. O cérebro e a mente, ou melhor, o corpo e a alma, surgem como fatos inseparáveis, "que somente podem ser recebidos e discutidos mantendo-se uma tensão criativa, como unos, ainda assim distintos [...]" (FISCHER, 2013a, p. 79). A pessoa é sempre mais do que a soma de suas partes, pois "pensar e sentir são características das pessoas, e não propriedades de suas partes [...]" (BENNETT, et al., 2010, p. 20). 
À luz das referências sugeridas, argumenta-se que o estágio atual das discussões em torno do tema aqui proposto não oferece pré-requisitos para sustentar o monismo reducionista e, isto, enquanto alternativa à crítica e rejeição feita ao dualismo cartesiano clássico. "O reducionismo proposto nas neurociências não dá conta de uma antropologia que se aproxime do que é o ser humano, tampouco o já referido dualismo" (FISCHER, 2013b, p. 95).

A partir da crítica aos dualismos cartesiano e estrutural torna-se possível tangenciar duas áreas de saber de interesse para o conhecimento teológico de tradição cristã, ultrapassando, desse modo, a abordagem tipicamente filosófica até aqui apresentada. Estas, que são a ética e a pastoral. A fé cristã se fundamenta no axioma de que Deus tomou a iniciativa, em Jesus Cristo, no propósito de reconciliar tudo o que divide, promovendo, desse modo, a dignidade humana como um valor transcendente; ética e cuidado pastoral são ações que não são dualizáveis. As escrituras bíblicas, em seus dois testamentos, estão repletas deste testemunho que aponta para a reconciliação com Deus e entre os seres humanos, entre as quais a passagem encontrada em Efésios 2 é basilar:

Pois ele é a nossa paz, o qual de ambos fez um e destruiu a barreira, o muro de inimizade, anulando em seu corpo a Lei dos mandamentos expressa em ordenanças. O objetivo dele era criar em si mesmo, dos dois, um novo homem, fazendo a paz, e reconciliar com Deus os dois em um corpo, por meio da cruz, pela qual ele destruiu a inimizade. Ele veio e anunciou a paz a vocês que estavam longe e paz aos que estavam perto, pois por meio dele tanto nós como vocês temos acesso ao Pai, por um só Espírito (Ef 2,14-18 NVI).

Este texto da carta destinada aos cristãos de Éfeso aponta para a destruição, na cruz de Cristo, de duas inimizades históricas, a dos que se consideravam povo de Deus pela observação da Lei mosaica e dos que viviam alheios a tais preceitos, os assim chamados gentios. A passagem, atribuída por grande parte dos pesquisados ao apóstolo Paulo, indica que no que se refere à reconciliação de tudo o que divide os seres humanos, a iniciativa cabe a Deus. Nem a observação da lei divina, nem sua negligência, se apresentam como alternativas para produzir a paz entre os seres humanos. Dualizar a compreensão de pessoa, escravizando o corpo pelos ditames dos deveres éticos impostos pela alma cartesiana moderna, ou 
negando a integralidade humana por meio de um reducionismo materialista, estruturalmente dualista, que rejeita, por fim, a responsabilidade humana por suas decisões e atos, indica a reprodução, hoje, no que se refere ao humano, de uma inimizade semelhante à apontada pelo apóstolo. Uma visão dualista ou reduzida da pessoa não promoverá a ética em assuntos que envolvam pesquisas com seres humanos. A mensagem da reconciliação cristã se apresenta como animadora de uma ética e de uma proposta de ação pastoral entre os seres humanos que toma a pessoa como ela é, apontando para um Deus de reconciliação, não de divisão:

Se a pessoa nada mais é do que um organismo particularmente complexo, se, inclusive, esta complexidade pode ser superada por máquinas, o que fica então do valor inviolável e imponderável de uma pessoa? [...] o projeto da naturalização ainda não progrediu tanto quanto alguns de seus defensores afirmam. [...] se faz necessário o discurso interdisciplinar que abre novas dimensões, porque as ciências naturais, a filosofia e a teologia encontram-se entrelaçadas intimamente entre si. Eu espero, com este discurso, ter oferecido uma contribuição em prol de uma imagem de pessoa integral, não dualista, como a pessoa, em meio aos desafios atuais, pode pensar a si mesma (BECKER, 2009, p. 256).

Filósofos e pensadores contemporâneos concluem que não mais é possível prosseguir defendendo uma visão de mundo destituída de sentido, na qual a dimensão teleológica da existência é negada. A natureza, de um modo geral, os animais e, especialmente as pessoas dão livre curso ao sentido. Estas últimas o buscam de modo permanente, como expressão de autoconsciência (NAGEL, 2013). Ainda que para muitos destes intelectuais deva-se encontrar na própria natureza as normas que orientam tal dimensão teleológica, transcendendo, desse modo, uma visão escrava da lei de causalidade, para as religiões, de um modo geral, a busca permanente de sentido atesta a presença de Deus nas pessoas, enquanto sua “'imagem e semelhança [...], colocando-o claramente acima dos animais" (MÜLLER, 2013, p. 38), mesmo que carente de reconciliação. A pessoa é alma vivente, organismo vivo, podendo-se apropriar aqui o testemunho cristão acerca da encarnação do próprio Deus: "Aquele que é a Palavra tornou-se carne e viveu entre nós" (Jo 1,14a NVI). Cada ser humano, pessoa, carrega esta imagem, apresentando-se como sujeito da ação 
reconciliadora de Deus em Cristo, para superação de todos os dualismos. São "objetos" de ações éticas interpessoais e da prática pastoral que testemunha o amor de Deus pela humanidade.

O intento de propor o diálogo entre ciência e fé não deve ter por meta uma espécie de encantamento do mundo. As pesquisas acerca da natureza humana e de tudo que o cerca devem seguir o seu curso. Porém, nenhuma área de conhecimento pode isolar-se em seu próprio saber. Há sempre outros conhecimentos que seguem a sua trajetória e, paralelamente, se apresentam como complementares. Não seria possível considerar todos os objetos de pesquisa, especialmente quando se trata do esforço para compreender o enigma do humano, em uma perspectiva de causalidade aberta? Afinal, são pessoas que percebem, pensam, recordam, emocionam-se, motivam-se, decidem e provocam ações, não seus cérebros.

A física Bárbara Drossel (2013) argumenta em prol de uma causalidade aberta na pesquisa científica, que não exclui abordagens explicativas do humano que se apresentam como complementares, uma vez que o ser humano sempre, de um modo ou de outro, se encontra implicado. Seu ponto de vista, embasado em exemplos de pesquisadores através da história das ciências, é de que esta causalidade aberta não fere esta lei da física, questionando tão somente o determinismo defendido por alguns cientistas da natureza:

Diante do fato de que as leis da natureza não fixam, por completo, o que transcorre no Universo, Deus pode agir no mundo sem que, com isso, viole continuamente as leis criadas por ele mesmo. Isto significa que o Universo é "aberto casualmente". Isto é, a propósito, semelhante às ações de nós, seres humanos, no mundo. Quando pensamos de modo lógico ou quando tomamos decisões, em nossas células cerebrais se desenvolve muita atividade elétrica. A distribuição exata desta atividade no espaço e no tempo não é, de antemão, quantificável e envolve uma mecânica quântica aleatória. Não há razão alguma para aceitar que, quando pensamos, alguma lei da natureza esteja sendo destruída. No entanto, se nossa atividade cerebral fosse, por completo, determinada, não poderíamos agir de modo livre, pois seríamos, antes, inteiramente definidos por meio do estado de nosso cérebro e do mundo material, do qual provêm suas impressões. O filósofo Karl Popper argumenta em seu livro "O Universo aberto", a favor de uma abertura causal 
do mundo. Este é um pressuposto para que, nas atividades que nele se desenvolvem, haja seres inteligentes (2013, p. 29-30).

No que diz respeito ao diálogo entre ciência e teologia, especificamente aquela que é proposta na tradição da fé cristã, Drossel reconhece a importância que se mantenham os limites e se discirnam as perguntas que as orientam, para que não ocorra sobreposição, um transbordamento de fronteiras:

Devido ao fato de que a fé e a ciência lidam com perguntas distintas, elas têm suas respectivas áreas de responsabilidade. À responsabilidade da ciência pertence a coesão interna do mundo, a saber, a descrição dos processos na natureza por meio das leis de causa e efeito e a busca dos princípios gerais por trás dessas leis. Assim, as ciências naturais estabelecem a pergunta pelo 'como'. O domínio da fé cristã, no entanto, é a revelação e o plano de salvação de Deus. Trata-se das perguntas pelo 'quem' e 'por que'. Como salientamos anteriormente, a fé está preocupada com a explicação 'pessoal' do mundo, sua origem e destino. Ela lida com os propósitos de Deus, seus critérios de valor e seu amor para com o ser humano. Se as responsabilidades da fé e da ciência forem confundidas chega-se a uma ultrapassagem de fronteiras, nas quais cientistas consideram poder dizer algo sobre o significado (ou falta de sentido) do Universo, e pessoas religiosas acreditam serem capazes, com base nas doutrinas bíblicas, deduzir algo sobre as condições da natureza (2013, p. 33).

Conclui-se, por meio da presente abordagem, que, na medida em que as ciências naturais avançam, especificamente as que estudam o cérebro humano, é fundamental que progridam também as discussões filosóficas que situam a pessoa como ser em busca permanente de sentido, um organismo vivo, alma vivente. Igualmente fundamental é, para a continuidade e o desenvolvimento da tradição teológica cristã, que se mantenha a confissão que identifique no humano a imagem e semelhança de Deus, alvo do testemunho acerca de seu valor inalienável e do amor de Deus.

\section{Considerações finais}

A intenção manifesta neste artigo foi tangenciar o tema da ética e da pastoral cristã, ainda que em defesa de um conceito de pessoa não dualista e nem reducionista. Reconhece-se, desse modo, que o assunto necessita 
prosseguir em seu livre curso, como é peculiar à teologia, enquanto área de conhecimento com interesses circunscritos e bem delimitados. No que diz respeito ao diálogo com as neurociências, por sua vez, é necessário que se aprofundem as percepções, como se propôs aqui por meio de uma discussão interdisciplinar, de caráter filosófico-teológico. A teologia, enquanto disciplina, não pode ausentar-se das discussões que se vêm propondo nos meios científicos, uma vez que envolvem a pessoa e a imagem que dele se faz. A reivindicação é que se façam correções contínuas na maneira de articular seu conhecimento, uma permanente crítica aos dualismos a que todo e qualquer pensamento humano se encontra sujeito.

\section{Referências}

BECKER, P. In der Bewusstseinsfalle?: Geist und Gehirn in der Diskussion von Theologie, Philosofie und Naturwissenschaft. Göttingen: Vandenhoeck \& Ruprecht, 2009.

BECKERMANN, A. Gehirn, Ich, Freiheit. Neurowissenschaften und Menschenbild. Paderborn: Mentis, 2008.

BENNETT, M. et al. Neurowissenschaft und Philosophie. Gehirn, Geist und Sprache. Berlin: Suhrkamp, 2010.

BÍBLIA SAGRADA: nova versão internacional [NVI]. São Paulo: Vida, 2000.

CASPARY, R. Alles Neuro? Was die Hirnforschung verspricht und nicht halten kann. Freiburg: Herder, 2010.

DROSSEL, B. Und Augustinus traute dem Verstand. Warum Naturwissenschaft und Glaube keine Gegensätze sind. Brunnen Verlag: Giessen, 2013.

ECCLES, J. C. Wie das Selbst sein Gehirn steuert. 2. ed. München: Piper, 1997.

ESPINOSA, N. A. Presentación. In: HERNÁNDEZ, C. J. La reflexión filosófica-teológica y el ejercicio clínico como actividades complementarias em la práctica psiquiátrica: una interpretación del "pensamiento para la psiquiatría" del Profesor Doctor Juan Ramón Sepich-Lange: 1905-1978. Posadas: EDUNaM, 2008. p. 17-21. 
FISCHER, G. J.; FACION, J. R. Uma nova imagem de pessoa? Neurociências e filosofia: possibilidades e limites. Revista Estudos Teológicos, São Leopoldo, v. 51, n. 2, p. 288-303, 2011.

FISCHER, G. J. A pessoa: fenômeno causal ou espontâneo? Exame crítico das objeções de Ansgar Beckermann à existência da alma. Revista Pistis \& Praxis, v. 5, n. 1, p. 59-90, jan./jun., 2013a. Disponível em: <https://periodicos.pucpr.br/index. php/pistispraxis/article/view/8672/8351>. Acesso em: 30/05/2016.

FISCHER, G. J. Sugestões para um cuidado pastoral de caráter unidual. Reflexões teológicas e antropoéticas. Revista Via Teológica, v. 14, n. 28, p. 75-104, dez., 2013 b.

GEYER, C. Vorwort. In: GEYER, C. Hirnforschung und Willensfreiheit. Zur Deutung der neuesten Experimente. Frankfurt am Main: Suhrkamp, 2004. p. 9-19.

JANICH, P. Kein neues Menschenbild. Zur Sprache der Hirnforschung. Frankfurt am Main: Suhrkamp, 2009.

LANGENSCHEIDT [Ed.]. Taschenwörterbuch Portugiesisch. Portugiesisch-Deutsch. Deutsch-Portugiesisch. Berlin und München: Langenscheidt Verlag, 2001.

LIBET, B. Haben wir einen freien Willen? In: GEYER, C. (Ed.). Hirnforschung und Willensfreiheit. Zur Deutung der neuesten Experimente. Frankfurt am Main: Suhrkamp, 2004. p. 268-289.

MORA, F. Continuum: como funciona o cérebro? Porto Alegre: Artmed, 2004.

MÜLLER, K. W. A consciência na cultura e na religião: vergonha e culpa como fenômeno empírico do superego/eu ideal: manual de elênctica. Curitiba: Esperança, 2013.

NAGEL, T. Geist und Kosmus. Warum die materialistische neodarwinistische Konzeption der Natur so gut wie sicher falsch ist. Suhrkamp Verlag: Berlin, 2013.

PAUEN, M.; ROTH, G. Freiheit, Schuld und Verantwortung. Grundzüge einer naturalistischen Theorie der Willensfreiheit. Frankfurt am Main: Suhrkamp, 2008.

SEARLE, J. R. A redescoberta da mente. 2. ed. São Paulo: Martins Fontes, 2006.

SINGER, W. Ein neues Menschenbild? Gespräche über Hirnforschung. Frankfurt am Main: Suhrkamp, 2003. 
414 FISCHER, G. J.

TRETTER, F.; GRÜNHUT, C. Ist das Gehirn der Geist? Grundfragen der Neurophilosophie. Göttingen - Bern - Wien - Paris - Oxford - Prag - Toronto Cambridge, MA - Amsterdam - Kopenhagen - Stockholm: Hogrefe, 2010.

VOGELSANG, F.; HOPPE, C. Ohne Hirn ist alles nichts. Impulse für eine neuroethik. Neukirchen-Vluyn: Neukirchener, 2008.

Recebido: 29/11/2016

Received: 11/29/2016

Aprovado: 05/03/2018

Approved: 03/05/2018 